\title{
Mast Cell Expression in Periodontal Ligaments Associated with Orthodontic Tooth Movement with the Use of Elastic Separator and Steel Ring in Nesolagus netscheri- In Vivo Study
}

\author{
Christian Andri Syahputra1, Trimurni Abidin², Nurhayati Harahap ${ }^{3}$ \\ ${ }^{1}$ Department of Master Science Dentistry, Universitas Sumatera Utara, Medan Indonesia. ${ }^{2}$ Department of Conservative \\ Dentistry, Universitas Sumatera, Utara, Medan, Indonesia. ${ }^{3}$ Department of Orthodontics, Universitas Sumatera, Utara, \\ Medan, Indonesia.
}

\section{ABSTRACT}

\section{BACKGROUND}

In orthodontic tooth movement, inflammation occurs physiologically which is a sign of the onset of the tooth movement process, where changes in mast cells are known as one of the representations of the early stages of the inflammatory process. One simple model for viewing orthodontic tooth movement is through the use of a separator on the teeth before molar band installation. This study aims to determine changes in the number of mast cells of the periodontal ligament space in orthodontic tooth movement between the use of elastic separator and steel spring based on the time of $0,3,5$, and 7 days.

\section{METHODS}

This type of research is an experimental laboratory. The subjects of the study consisted of twenty male rabbits, five rabbits as a control group which was not treated, five rabbits as group 0 day, five rabbits for group 3 days, five rabbits for group 5 days, five rabbits for group day 7. Each right mandibular molar tooth is fitted with steel spring, and the left pair is paired with elastic separator. Then the rabbit's jaw is resected, and each periodontal ligament area was given toluidine blue to calculate the number of mast cells in that area.

\section{RESULTS}

The results showed no significant differences in the number of mast cells due to administration of elastic separator and steel spring ( $p>0.05$ ). But it can be seen that there is a difference in the number of mast cells increasing faster in steel spring starting from the group days 0 to day 5 compared to the elastic separator and in the group of 7 days there are not much difference with the use of steel spring and elastic separator.

\section{CONCLUSIONS}

There was no difference in the number of mast cells in orthodontic forces with the use of elastic separator or steel spring, although based on the time of use there was an increase in mast cells faster when steel spring was used compared to elastic separator.

\section{KEY WORDS}

Elastic Separator, Inflammation, Steel Spring, Mast Cells, Orthodontic Tooth Movement

\author{
Corresponding Author: \\ Trimurni Abidin, \\ Department of Conservative Dentistry, \\ Faculty of Dentistry, \\ Universitas Sumatera, \\ Utara, Medan, Indonesia. \\ E-mail: triabidin@yahoo.com
}

DOI: $10.14260 /$ jemds/2019/862

Financial or Other Competing Interests: None.

How to Cite This Article:

Syahputra CA, Abidin T, Harahap N. Mast cell expression in periodontal ligaments associated with orthodontic tooth movement with the use of elastic separator and steel ring in nesolagus netscheri- in vivo study. J. Evolution Med. Dent. Sci. 2019;8(52):3989-3993, 10.14260/jemds/2019/862

Submission 18-06-2019,

Peer Review 02-12-2019,

Acceptance 12-12-2019,

Published 30-12-2019. 


\section{BACKGROUND}

The movement of teeth in the oral cavity with the application of orthodontic power is indicated by changes in remodelling of the teeth and supporting tissues, including the dental pulp, periodontal ligament, alveolar bone, and gingival tissue. This type of tooth movement shows unique signs with the presence of compressions and pulls on the periodontal ligament. This phenomenon is explained through a theory called the theory of pressure and pull (Pressure Tension Theory) and is considered as the main mechanism responsible for orthodontic tooth movement. ${ }^{1}$

The initial conditions for remodelling and tooth movement activities are a result of the inflammatory process. Two processes that are interconnected so that tooth movement occurs in orthodontic treatment are: (1) deflection or bending of alveolar bone and (2) remodelling of periodontal tissue, including pulp tissue, periodontal ligaments, alveolar bone and gingival. The strength given causes compression/ pressure of the periodontal ligament on one side, while in the other part the periodontal ligament experiences pulling. ${ }^{2.3}$

Several studies have shown changes in connective tissue associated with orthodontic tooth movement through experiments, and concluded that the mechanics of tooth movement causes an inflammatory process in periodontal tissues. The preconditions of this remodelling activity and tooth movement trigger the inflammatory process. Vascular and cellular changes are the first events that occur and can be recognized, then followed by the emergence of a number in inflammatory mediators, growth factors and neuropeptides in periodontal supporting tissues. ${ }^{4}$

Changes in biological conditions due to mechanical stress that causes mild and continuous orthodontic tooth movement will be known by the systemic body as a physiological movement. The presence of periodontal ligament compression will lead to the hyalinisation process of connective tissue, direct resorption or undermining resorption of the alveolar bone which then triggers orthodontic tooth movement. 5

One study suggested that the orthodontic strength given would result in the same tissue changes and inflammatory reactions, both in the periodontium and dental pulp. This process activates inflammatory mediators such as prostaglandin, interleukin (IL)-1, UK-6, Tumour Necrosis Factor (TNF) and nuclear factor receptor activation of Ligand $\mathrm{Kb}$ in the periodontal ligament and dental pulp. Levels of inflammatory mediators in osmotically gingival crevicular fluid will mediate inflammatory exudates in the gingival sulcus which will significantly increase during orthodontic treatment. ${ }^{6}$ Yamasaki et al. in their experimental study to look at orthodontic tooth movement in mice, found the magnitude of the role of prostaglandin as a biochemical mediator. This can be seen by the synthesis and secretion of prostaglandin by localized cells, which then triggers the occurrence of bone resorption by osteoclast. ${ }^{7}$

Meikle stated that inflammatory cells can generally be seen around blood vessels near the periodontal ligament, or near the epithelium junction boundary that regulates the host's immune response. These cells include lymphocytes, plasma cells, mast cells and macrophages. Mast cells are widely known for their role in the process of allergies and anaphylaxis, besides mast cells also play an important role in wound healing, and defence against pathogens. ${ }^{5}$

Rivera and Gilfillan reported a study that mast cells are secretory cells of connective tissue that originate from the spinal cord circulation and have important functions in the inflammatory process and immunity. Mast cells are found in all parts of the body's tissues, especially those associated with connective tissue structures such as blood vessels, lymph vessels, nerves, and borders that connect with the external environment such as breathing, skin, and digestive tract. Mast cells are the first few cells to initiate a defence mechanism. Mast cells also synthesize and release serine and metalloprotease which cause cellular matrix degradation and tissue changes. This function causes mast cells to have a strategic function to organize tissue defence, restore tissue damage and control network homeostasis. ${ }^{8}$

In orthodontic tooth movement, physiological information is a sign of the onset of the tooth movement process, where changes in mast cells are known as one representation of the initial stages of the inflammatory process through the excretion of chemical mediators and enzymes that affect the inflammatory process. A simple model for seeing orthodontic tooth movement is through the use of a separator on the tooth before molar band installation. According to study by Ren et al, the use of separators is needed to create enough space between the teeth a few days before molar band, ${ }^{9}$ installation is performed. There are several types of separators commonly used, namely elastic separator, steel spring, and brass wire. The duration of placement of the separator itself according to Pavlin and Gluhak-Heinrich's study takes 2-3 days,10 while Proffit believes that the use of separators should not be used for more than 2 weeks. ${ }^{11}$ Until now information about the role of mast cells in the movement process teeth are still very limited. The purpose of this study was to find out about changes in the number of mast cells in the periodontal ligament space in orthodontic tooth movement if elastic separator and steel spring were used in the installation of the two devices within $0,3,5$ and 7 days.

\section{METHODS}

\section{Research Subjects}

In this study the research subjects were 25 male rabbits (Nesolagus Netscheri), an average age of 4-5 months with a body weight of $1.8-2 \mathrm{~kg}$. Rabbits are divided based on the time of treatment group using elastic separator and steel spring, which is $0,3,5$ and 7 days and the control group is not given a separator.

\section{Preparation of Animals Trial}

Before the separator was installed all the animals were tested on IP anaesthesia with Ketamine $\mathrm{HCl} / \mathrm{BB}$, then the elastic separator was installed in the lower right molar and steel wire in the lower left molar. The experimental animals were divided into 5 (five) groups consisting of 5 rabbits for each group, namely: Group 1 as a control group was not installed separator, group 2, separator was installed, then rabbits were killed on the same day after installation of separator 2 hour; group 3, separator and rabbit were installed and rabbits were killed on the third day; group 4, installation of separator was 
carried out then the rabbit was killed on the fifth day; group 5 , separator was installed, then the rabbit was killed on the seventh day.

\section{Preparation of Specimens}

Specimen extraction was carried out by performing bone dissection in the mandibular region of the interradicular part of the tooth that was installed by the separator, according to the treatment group, and then decalcified with formic acid for one week. Cutting was done mesiodistal in each part of the treated tooth with a thickness of $7 \mathrm{~m}$.

\section{Specimen Staining Preparation with Toluidine Blue}

Each part of the specimen is stained with toluidine blue to detect mast cells. Histologic examination was carried out on specimens obtained in the interradicular septal region and lingual roots of the right and left mandibular first molars according to the type of separator installed. Mast cells are calculated in a predetermined area of the periodontal ligament of each interradicular septum made in each of the 5 specimen sections, namely for the distal part of the periodontal ligament and the interradicular septum of the first molars as the pressing area and the mesial part which is the withdrawal side. The criteria for identification of mast cells is metachromatic staining with toluidine blue which was observed with a light microscope. The measurement of the number of mast cells is carried out in an average of the number of mast cells seen with the colouring.

\section{Data Analysis}

All data are presented in mean \pm SD. Test the normality and homogeneity of the data. Test for normality and homogeneity. If the data is normally distributed and homogeneous tested with Paired t-test and one-way ANOVA. If data is not normally distributed or not homogeneous, data transformation needs to be done. Then tested again the normality and homogeneity of data. If the data is not normally distributed or not homogeneous, then it is tested by the Friedman test to see the differences between the control group and the treatment group. And the Wilcoxon Signed Rank Test was conducted to determine the difference in the number of mast cells in the periodontal ligament due to orthodontic strength between elastic separator and steel spring on the first day of installation, day 3,5 and 7 .

\section{RESULTS}

The results of this study are by giving orthodontic power to the test animals there are differences in the number of mast cells decreasing compared to the number of mast cells in the control group, where in the control group in steel spring the average number is 2.92 then post-administration of orthodontic power drops to 2.64 on day 0 ( 2 hours after application of steel spring). With a comparison in the experimental group on day 3 mast cells became an average of 2.88. The results of the observations showed that there was a gradual increase in group 5 days where mast cells became an average of 3.08 and in the 7 th day group it was 3.12 (Table 1).

With the application of orthodontic power to the experimental group using elastic, it was also found that there was a clear decrease in the control group to the 0 day group (2 hours after the elastic separator application).

\begin{tabular}{|c|c|c|}
\hline & Steel Spring SD & Elastic Separator SD \\
\hline Control & $2.92 \pm 0.81$ & $3.00 \pm 1.04$ \\
\hline 0 day ( 2 hours) & $2.64 \pm 0.86$ & $2.36 \pm 0.81$ \\
\hline 3 days & $2.88 \pm 0.78$ & $2.76 \pm 0.88$ \\
\hline 5 days & $3.08 \pm 0.91$ & $2.84 \pm 0.85$ \\
\hline 7 days & $3.12 \pm 0.67$ & $3.08 \pm 0.76$ \\
\hline \multicolumn{3}{|c|}{$\begin{array}{c}\text { Table 1. Number of Mast Cells after Administration of Orthodontic } \\
\text { Power with Elastic and Steel Spring in the Experimental Group and th } \\
\text { Control Groups } 0,3,5 \text { and } 7\end{array}$} \\
\hline
\end{tabular}

The movement of teeth using steel spring, which is seen using mast cell markers, shows a decrease in the number of mast cells at the time of giving power after the first day to the 3rd day, then increases on day 5 and stabilizes on day 7. With a stable amount mast cells show desired tooth movement results (figure 2).

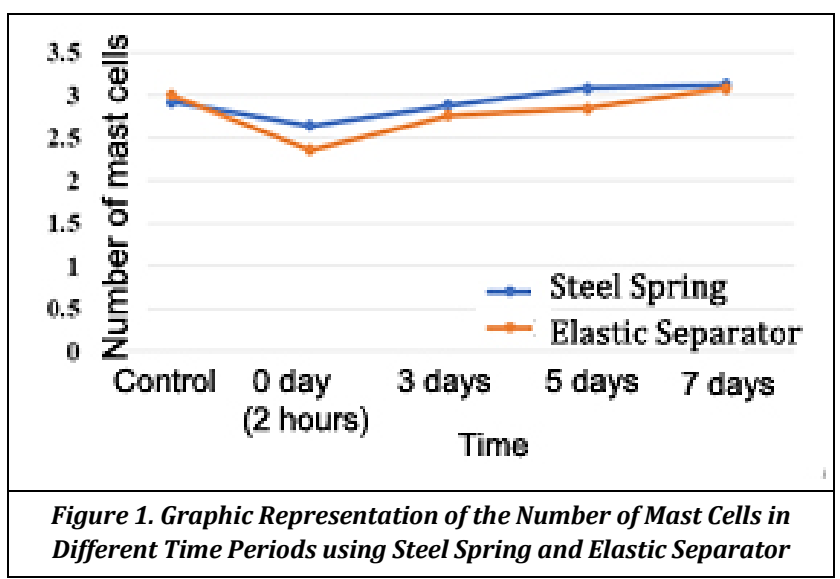

Movement of teeth with elastic seen using mast cell markers, showed a decrease in the number of mast cells more at the time of giving power after the first day to the third day compared to steel spring, then it will increase gradually on days 5 and 7 (Figure 3). The movement of spring and elastic steel on the 7th day showed that the number of mast cells was not significantly different. The difference is only in the speed of movement, which is between days 3 and 5, and will achieve the same number of mast cells on day 7 .

\begin{tabular}{|c|c|c|c|c|c|c|c|}
\hline \multirow{4}{*}{ Group } & \multicolumn{2}{|c|}{ Kolmogorov-Smirnov } & \multicolumn{3}{|c|}{ Shapiro-Wilk } \\
\cline { 3 - 8 } & & Statistic & df & Sig. & Statistic & df & Sig. \\
\hline \multirow{3}{*}{$\begin{array}{c}\text { Number } \\
\text { of mast } \\
\text { cell }\end{array}$} & Control & .260 & 25 & .000 & .886 & 25 & .009 \\
\cline { 2 - 8 } & 0 day (2 hours) & .265 & 25 & .000 & .850 & 25 & .002 \\
\cline { 2 - 8 } & 3 days & .312 & 25 & .000 & .787 & 25 & .000 \\
\cline { 2 - 8 } & 5 days & .238 & 25 & .001 & .824 & 25 & .001 \\
\hline
\end{tabular}

Table 2. Test for Normality b/n Control Groups and Treatment Groups

\begin{tabular}{|c|c|c|}
\hline Group & Mean Rank & p \\
\hline Control & 3.14 & \multirow{2}{*}{0.084} \\
\hline 0 day (2 hours) & 2.36 \\
\hline 3 days & 2.96 \\
\hline 5 days & 3.06 \\
\hline 7 days & 3.48 \\
\hline \multicolumn{2}{|c|}{ Table 3. Friedman Test- Differences between } \\
Control Groups and Treatment Groups \\
\hline
\end{tabular}

\section{Lilliefors Significance Correction}

From table 2, data can be seen between the control group and the treatment group based on the observation time, the data are not normally distributed ( $\mathrm{p}<0.05$ ). Therefore, Friedman test was conducted to see whether there were differences 
between the control group and the treatment group, it turned out that the results showed no difference between treatment groups ( $p>0.05$, Table 3). To see whether there are differences in the number of mast cells in the use of elastic separator and steel spring, a Wilcoxon test was performed, and the results showed no difference between the two separators ( $p>0.05$, table 4$)$.

\begin{tabular}{|c|c|c|c|c|c|}
\hline & & $\mathbf{N}$ & Mean Rank & Sum of Ranks & p \\
\hline \multirow{4}{*}{$\begin{array}{c}\text { Steel Spring } \\
\text { - Elastic } \\
\text { Separator }\end{array}$} & Negative Ranks & $27^{\mathrm{a}}$ & 33.89 & 915.00 & \multirow{4}{*}{0.202} \\
\hline & Positive Ranks & $39^{b}$ & 33.23 & 1296.00 & \\
\hline & Ties & $59 \mathrm{c}$ & & & \\
\hline & Total & 125 & & & \\
\hline
\end{tabular}

Table 4. Wilcoxon Signed Ranks Test- Differences in the Number of Mast Cells in the use of Elastic Separator and Steel Spring

a. Steel Spring < Elastic Separator.

b. Steel Spring > Elastic Separator.

c. Steel Spring = Elastic Separator .

\section{DISCUSSION}

Research on the difference in the number of mast cells in the periodontal ligament is associated with orthodontic tooth movement through the use of elastic separator and steel spring in rabbit experimental animals. This study aims to determine changes in mast cells which are known to represent the early stages of the inflammatory process as biological responses arising from orthodontic tooth movement. Mast cells themselves are generally inflammatory cells that can be seen around blood vessels near the periodontal ligament or near the boundary of the epithelium junction that regulates the host's immune response. Mast cells are widely known for their role in the process of allergies and anaphylaxis, they also play an important role in wound healing and defence against pathogens. ${ }^{8}$ In orthodontic tooth movement, physiological inflammation is a sign that the tooth movement process begins, where changes in mast cells are known to be initiators inflammatory process through excretion of chemical mediators and enzymes that affect the inflammatory process.

The sample used was male rabbits aged 4-5 months with a body weight of $1.8-2 \mathrm{~kg}$ because the age had passed the age of the growth of the teeth. Previously this study referred to the research conducted by Yamasaki et al. by looking at the effects of prostaglandin on the number of osteoclasts and root surface resorption in orthodontic tooth movement with animals in male Sprague-Dawley mice. ${ }^{7}$ However, the researchers found it difficult to replace research with rabbits as rabbits had a larger body size, and larger teeth so that the apparatus applied, the orthodontic separator can be applied well to the rabbit's teeth. In addition, the selection of male rabbits is done in order to obtain a hormonal balance for the validation of the results of the study.

In this study an elastic separator and steel spring tool was used as a simple model to see the existence of orthodontic tooth movement. Clinically the use of elastic separator and steel spring is usually used to prepare space on the mesial and distal sides of the molar teeth before molar band installation. The duration of placement of separators according to Pavlin and Gluhak-Heinrich is for $2-3$ days, ${ }^{10}$ while Proffit argues that the use of separators should not be used for more than 2 weeks. ${ }^{11}$ This is the basis for observing changes in the number of mast cells carried out in groups 0,3 , 5 and 7 days.

The results of this study are similar to those obtained by Yamasaki et al who also observed a decrease in mast cells in the use of elastic bands between the first molars and second molars and were seen also with toluidine blue stain, in the periodontal ligament both on the pressure and pull side of the tooth Sprague - Dawley rats. ${ }^{7}$ Only in this study were observations carried out only on one side, but with different observations at $0,3,5$ and 7 days. In this study the reduction of mast cells in the use of separators in orthodontic treatment was seen to decrease at 0 days ( 2 hours), both in the use of steel spring and elastic separators. This is presumably due to the degranulation process of intracellular granules, followed by increased vascular permeability, degenerative and reformative changes of the periodontal ligament. This stimulates the synthesis and secretion of prostaglandins and is followed by bone remodelling. Weissler et al. have reported the role of prostaglandins (PG's) as precursors of components of cell membrane lipids which are a biochemical mediator of bone resorption as a result of the administration of orthodontic treatment. ${ }^{12}$

In this study it was seen that after 2 hours of use of the separator there was a decrease in mast cells in the results of toluidine blue staining as an increase in vascular permeability. Changes in mast cells are characterized as the initial stages of inflammation due to excretion of the chemistry of mediators and enzymes involved in the inflammatory process. Mast cells contain mucopolysaccharide acid as an example of heparin, some groups of amines include histamine, serotonin and enzymes. These active biological materials are stored in intracellular granules. Metachromatic reactions from mast cells to mast cells are caused by mucopolysaccharide acid. Stimulation of cells causes extrusion of these materials and causes mast cells to lose stainability to fluidine blue. The decrease in the number of mast cells in toluidine blue staining was thought to indicate that the reaction had begun. The difference in the results of this study with the research of Yamasaki et al. is a decrease in mast cells in the installation of elastic separator with toluidine blue staining is 15 minutes after installation of separator, while in this study it was seen in 2 hours of installation. ${ }^{7}$

The increase in the number of mast cells was seen on days 3 and 5 of this group of steel spring separators compared to elastic separators. It can be said that steel spring triggers higher inflammation so that the expected tooth movement occurs. On days 5 and 7, the number of mast cells is no different. This can be expected because the reaction of the periodontal tissue to the power given is very dependent on the strength, frequency and duration received by the tooth being moved. ${ }^{2}$ On the other hand, the elastic separator shows more decrease in mast cells in the initial use ( 2 hours) than steel spring, but increases on days 3, 5 and 7 days. This is thought to be due to a decrease in the ability of the elastic separator because it is made of rubber so that the reaction caused decreases.

Movement of teeth in orthodontic treatment consists of (1) initial phase, (2) lag phase, and (3) postlag phase. This initial phase is characterized by immediate and rapid tooth movement that occurs within 24 to 48 hours after the 
application of power to the teeth. This is enough to move the teeth in the periodontal ligament space. ${ }^{3}$ In the use of the separator, the initial phase is needed for molar band mounting. In this case, it is not expected that further phases will occur such as tooth movement in subsequent treatments. Changes in the number of mast cells from day 5 to day 7 which look almost the same shows tissue reactions that reexperience homeostasis from cells in the periodontal ligament environment, so as not to cause damage to tooth tissue and periodontal ligaments and unexpected alveolar bone in the installation of separators.

In this study, although the statistical results did not differ significantly, the use of a good separator with steel spring and elastic showed differences in changes in the number of mast cells in the use of steel spring and elastic separators based on observations of time which is at $0,3,5$ and 7 days.

\section{CONCLUSIONS}

Based on the results of research on differences in the number of mast cells in the periodontal ligament space associated with orthodontic tooth movement through the use of steel spring and elastic separator, it can be seen that there was no significant difference in the number of mast cells by the application of steel spring and elastic in the $0,3,5$ and 7 day groups. Decreased mast cells occur on day 0 ( 2 hours) after use in either the steel spring or elastic separator. Entering the $3^{\text {rd }}$ day and $5^{\text {th }}$ day there was a slight increase in the number of mast cells in the group by giving a steel spring application compared to the elastic separator. Entering the $7^{\text {th }}$ day both spring and elastic steel separators show almost the same number of mast cells, which means inflammation in the periodontal ligament decreases with the occurrence of homeostasis of all the cells in the periodontal ligament. It can be concluded that in orthodontic tooth movement, mast cells are markers that can be seen in the presence of initial inflammation that allows tooth movement.

\section{REFERENCES}

[1] Krishnan V, Daviddovitch Z. Biological mechanism of tooth movement. Blackwell 2009(1):1-96.

[2] Dolce C, Malone JS, Wheeler TT. Current concepts in the biology of orthodontic tooth movement. Seminars in Orthodontics 2002;8(1):6-12.

[3] Krishnan V, Davidovitch Z. Cellular, molecular and tissue-level reactions to orthodontic force. Am J Orthod Dentofacial Orthop 2006;129(4):469.e1-e32.

[4] Krishnan V, Davidovitch Z. On a path to unfolding the biological mechanisms of orthodontic tooth movement. J Dent Res 2009;88(7):597-608.

[5] Meikle MC. The tissue, cellular and molecular regulation of orthodontic tooth movement: 100 years after Carl Sandstedt. Euro J Orthod 2006;28(3):221-40.

[6] Yamaguchi M, Kasai K. Inflammation in periodontal tissues in reponse to mechanical forces. Arch Immunol Ther Exp 2005;53(5):388-98.

[7] Yamasaki K, Miura F, Suda T. Prostaglandin as a mediator of bone resorption induced by experimental tooth movement in rats. J Dent Res 1980;59(10):163542.

[8] Rivera J, Gilfillan AM. Molecular regulation of mast cell activation. J Allergy Clin Immunol 2006;117(6):1214-25.

[9] Ren Y, Maltha JC, Kuijpers-Jagtman AM. The rat as a model for orthodontic tooth movement - a critical review and proposed solution. European J Orthodontics 2004;26(5):483-90.

[10] Pavlin D, Gluhak-Heinrich J. Effect of mechanical loading on periodontal cells. Critical Reviews in Oral Biology and Madicine 2001;12(5):414-24.

[11] Profitt WR, Fields WH. Contemporary Orthodontics. St. Louis, Mosby Inc., $3^{\text {rd }}$ edn. 2000: p. 296-304.

[12] Weissler A, Mekori YA, Mor A. The Role of mast cells in non-allergic inflammation. Isr Med Assoc J 2008;10(12):843-5. 